\title{
Edwin Thumboo Interviewed by Peter Nazareth*
}

$P N$ : Edwin, I am going to read something to you. See if you recognize the poem:

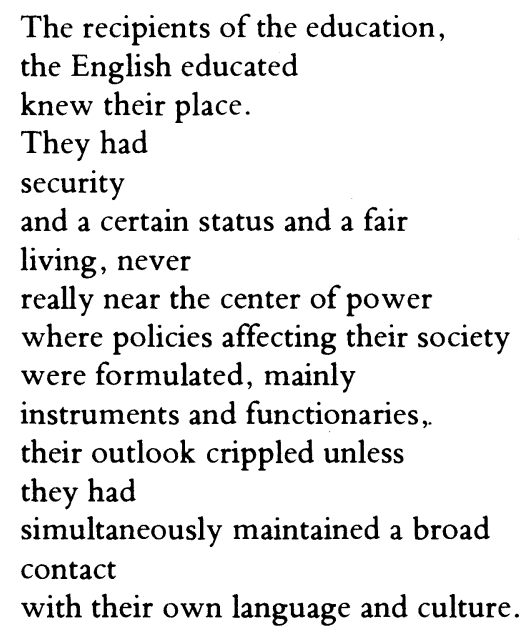

$E T$ :That isn't a poem! That's from a lecture I gave at Singapore's Nanyang University in late 1975!

$P N$ : Yes; but do you agree that there is a poetic quality in those lines?

ET: Perhaps. The idiom of contemporary poetry has reached a point where it is very close to prose. Moreover, the point I was making in that lecture lies very close to our fundamental thinking. The history of the last two hundred years in our part of the world was made by colonial incursion. As a reaction to that, we must re-think, re-write and reorientate our history. Such a revitalization of our history deals with large entities, large problems. In the meantime, people live. In that passage, whatever the aesthetic quality, I tried to capture our sense of that almost hidden essence of our lives. What I was and what I am really concerned with is social history: the intimate decisions and events within families. Not with governments or other centers of formal power.

$P N$ : Isn't language one of those entities you have been most conscious of? The colonial inheritance . . . the fact that the English language itself has carried the burden of that inheritance within it? You deal with those questions in your introduction to The Second Tongue: An Anthology of Poetry from Malaysia and Singapore. And the most pressing issue is the one with which I began ... : Are you conscious of compressing language in such a way that your audience is not aware that the prose is poetry or, to put it the other

${ }^{*}$ Condensed by us from a much longer interview. F.W. and D.H. 
way round, are you trying to write a poetry which people are not aware is poetry?

ET: There are really two answers to your last question: Yes and No. Yes because, in the context of the lecture and the occasion, I was conscious that my topic was about a crucial problem which the audience itself was living through. In the passage in question (and certainly in others), I attempted to represent the substance of the problem in language that was as intense, resonant, and suggestive as I perceived our consciousness of the problem to be. As I think of it now, the rationale for doing so is a simple approach to a complex situation. In our part of the world, it is important to stress that contemporary history, the great flux of events and the forces of change move rapidly, are concertina-ed; within a period of ten years of contemporary life, one may experience change and dislocation, the equivalence of which, in other parts of the world, have taken as much as four hundred years to run their course. You may find, within the Singapore of the last ten years, that world-views, attitudes toward social, political, and economic issues, questions about education and an emergent culture, have evolved at an incredible rate. Because we live at a time and in a situation in which change is the order of things, you may find-comparatively speaking-the thinking of four generations compressed into one. That gradual evolution, that slow passing down of ideas, their slow and orderly revision, occur now under hot house conditions.

Then there is my "no" to your question. First, let me say that I am sure that, on some aesthetic scale, the passage you quoted as a poem, is indeed a poem; and, if that be the case, the credit for its artistry is yours. For it was your imagination that perceived the possibility for arranging the words in the form the passage now takes. But to place the passage in the context of my original intention, I had not intended it to be a poem. You mentioned my introduction to The Second Tongue. Well, in that introduction, I made a simple statement about language which is worth my remembering: "language must serve, not overwhelm if the Commonwealth writer is to succeed." The "no" to the questions centers rather squarely upon my sense that, as a poem, words in a "poetic form" overwhelm. As prose lines, my words had a complementary context to reflect their meaning; as poetry, those lines, so delicately woven into a form that shapes its own context, are alien to that for which I designed them. As a "poem," those lines remind me of poetry written by younger people today, poetry which seems very much the kind you find elsewhere by the youth in English-speaking parts of the world. As such, it reflects the poetry of urban settings; it is the poetry that inspects, that glides softly at the edges of history and then comes back to project the position of the individual in society, his reactions, his emotional curve, as it were, all in an evermore rapidly urbanizing world.

$P N$ : Is the tension in what you're saying the tension of contradiction?

$E T$ : I'm not sure I understand. 
$P N$ : Are you saying, in other words, that what I designed as a poem is not a poem because you did not mean those words to be poetic?

$E T$ : Again, you give me a yes and no question.

$P N$ : Isn't that a contradiction?

$E T$ : No. Because I have differentiated the contexts and forms that ...

$P N$ : In one form and context, the utterance is a public and communal perception; but in another, it is a personal-hence, private and individualutterance? If you're not dealing in contradiction, then, at least, ambiguity? ET: I agree to neither. As I used the passage-that is still our point of reference, I trust-as I used the passage in my lecture I meant it to have the benefit of the history and form that the prose context gave it. In that regard the passage gained an integrity which, for my intention, could not be gained otherwise. Alone, as an existential entity - a poem-the passage is flat; its brief moment, its movement and form are its all, everything; and, as such, it is overwhelming. Or maybe it falls flat, has no force at all.

$P N$ : You yourself have served in multiple roles in Singapore. You've been a civil servant, very much involved in the process of change. Then you moved into the academic world as a teacher. And you are a poet. You are using the language to help bring about change rather than to be overwhelmed by change. How do you differentiate your use of language as a bureaucrat? As a teacher? How does your language change when you concentrate on writing poems.

ET: The language of the civil servant is disarmingly simple. After all, civil servants think of different ways of saying "yes," different ways of saying "no"; their decisions are backed up by ordinances, by-laws, and so on. The excitement of civil servicing comes when one meets with a problem that lies outside the "yes and no" kind of situation. Basically, a civil servant makes a decision and explains it. If the decision is "yes," perhaps less explanation is needed. When the decision is "no," then, as a civil servant, a functionary of government, ultimately responsible to the people, one has to explain why it is "no."

In Singapore, where you have some twenty-three languages and dialects among three ethnic communities-with perhaps a fourth one, the Eurasians-the impartial use of a civil service, and therefore the impartial rhetoric of a civil service, is extremely important. We inherited a pretty solid civil service from the British. We have modified and extended that tradition. The British tradition of civil service, for better or worse, was impartial-if nothing else. When I say, "impartial," I mean in the day-to-day management of things. As you know, for example, Asian societies are by and large chauvinistic societies; and, within the chauvinism, there is nepotism: brother knows brother, knows uncle, knows grand-uncle or whatever as the network of power extends. An impartial civil service could break through that kind of kinship system by insisting upon impartiality. The tradition we inherited was thriving; and our government, among the most sensible in Third 
World countries, maintained the tradition, so that the rhetoric of the civil servant means that you explain, that you justify, that you educate.

The second role you mentioned, that of the teacher, ties in very readily with the Asian "guru" tradition. As a teacher, one is interested not merely in educating people but also in engendering people who will develop beyond their earlier selves. Language, here, is the freest of tools; that is, it is the most personal on the one hand and the most public on the other. One is really educating people in the possibilities of the culture in order that they may take over and extend the culture by consolidating the vision of which we are part.

For the university teacher, the use of language is very broad. At one extreme, when it comes to the teaching of literature in English-and by that I mean not merely Shakespeare but also the African writer, Ngugi, and, when I return to Singapore, perhaps Peter Nazareth-one makes use of language in one of the most "totally humanistic" senses possible: as an instrument of criticism in the pursuit of an understanding of literature as a discipline, and as an instrument of creative expression. In a Third World country, one cannot simply plug into an orthodox lingo-a Leavisite criticism, say-as can the teacher in a redbrick British university. For us, language, literature is not merely a discipline; we are too close to the processes of our formation for so simple a luxury.

As for the creative mode of using language against the critical: the first point I would like to make is that every creator must be a critic of a very personal kind. For the serious artist/practitioner this means that a poem, a short story, a novel, a play or whatever must be subjected to different drafts; and these drafts, mind you, are not so much ritual for the sake of ritual as they are hairpin thrusts upon the tumblers of a lock; and each thrust is a critical act, an act of patient desperation which binds the writer to his purpose and audience. Let me clarify: I would love to write intense, internalized, interiorlandscape poetry. Such is probably my real forte. A recent reviewer of my volume, Gods Can Die, writes of how my poetry develops-changes, since the word, "develops," seems a value judgment implying "improvement." The reviewer notes that my early poems are lyrical and the later ones more public. But I consciously made the change as a choice of a poet in a particular setting; and I made that choice with perhaps the fullest understanding of my preference for writing the poetry of interior monologue. But a poet in Singapore, and especially someone from my generation, has certain responsibilities.

I recall, with a certain acuteness, a kind of anti-colonial feeling which was most vivid in Singapore-as a pro-nationalist feeling rather than as anticolonial feeling. I recall that period; it left its mark on me. At the height of that period, I recognized that the poet of my generation has a certain public function. I felt quite clearly that the poet in London must have his preoccupations; and that, if a novelist in America wanted to write about the problems of lining up for bread, that's his affair. I could not be about the business of suggesting how he should write what he felt moved to create. But I knew I 
was compelled to exercise what I felt to be my function in my society; and, from that choice stems certain attitudes toward language, structure, toward the purpose of poetry. And from those attitudes my poetry takes form.

The generation of poets after mine, those who started writing in the sixties, seem to have a concern for social issues as well as for issues of a more personal kind. Questions of personal identity, "What are the problems that confront me as an individual?" "How do I live?" suggest themselves with more force than ever before. And the younger people, in their teens and early twenties, are now writing a very powerful kind of personal poetry, the poetry of the "I."

$P N$ : I note that, in your poetry, you often try to keep the lid on your emotions.

ET: Yes. Most often, certainly.

$P N$ : If you express emotion, it is by the way you order the facts. You appear just to objectively describe a person or a situation; and it might look neutral; but the very organization of facts convinces. It is the opposite of declamation. $E T$ : I appreciate your observation.

PN: But do you consider your style to be very much a response to the Singaporean situation: the fact that, as you say in one of your poems, "Singapore is just a boil on the Melanesian face?"

ET: You've touched on a very complex question, one which the line you've quoted, perhaps, disguises. What you are really asking, albeit differently from the first, is what makes a poet write the way he does? Meaning, futhermore, why are the words from my 1975 lecture at Nanyang University not a poem for me.

$P N$ : If that keeps the dialogue going, yes.

$E T$ : I only half jest, Peter. The question is an honorable one, be assured. A poet writes because he feels he has something to say. So first there is his vision. His vision is constructed through a series of influences: his teachers, his elders, his peers, through the kind of problems they define for him and that he comes to accept as vital in his society. These could arise from the details of political, social, cultural and linguistic issues and the broad themes suggested by them-in other words, response from the heart to the capillaries. For him it is a very conscious business because this is not just part of his poetry but part of his consciousness as a person.

There is also the poet's analysis of the immediate situation set against his sense of historical continuity. All of these things influence his choice of idiom, of form, of tone. You know the English language as well as I. We know that it is capable of expressing the most intensely personal feelings to the most broadly public ones. We can think of examples in English literature-we have been victims as well as inheritors of English literature, Peter. We can give examples from, say, Donne to Eliot to illustrate the diverse use of the language for different poetic purposes; and behind each, there is a different set of assumptions, a different set of interests, a different set 
of purposes. For someone writing in Singapore, intense personal poetry of the "ingrowing toenail" kind does have its place. But, given our situation as a developing country, that kind of poetry addresses itself to a very narrow segment of our readers. To begin with, in Singapore, if you wrote in English twenty years ago, you would have had about thirty readers; ten years ago you would have had fifty; and five years ago about two hundred. Today, you have at least five hundred readers. And this figure, based on the sale of books of poems published in Singapore, is rapidly increasing. In other words, if he is concerned with readership, if he is concerned that others should read his poetry, those figures will inevitably influence him. If he wants to reach people his style has to range into the public.

Why then, you ask, do my poems appear to be poems of fact? What I attempt to do in my poems is to project a point of view in the selection of the facts, in the arrangement of facts; but I also insist upon writing poetry. While I write poems that have public themes, I hope I create poems. Not propaganda. Yes, of course, propaganda is implicit; it is part of poetry, too; but it is my hope that it is the poetry that persuades not the propaganda. That is one of the fundamental issues in Third World writing.

PN: You said in your introduction to The Second Tongue that Singapore lacks a social history. In several of your poems, as well as in several poems you selected for the anthology, I notice a description of people as they are in Singapore-individuals, sometimes groups, bringing to the attention of other groups the existence of these people around them, whom they don't even know, don't notice. Is this a very quiet move towards nation-building? ET: I can draw two conclusions which are perhaps complementary. As I said earlier, we have the kind of history that relates to events and treaties. The larger history, the public history-we must have that. We are reorientating approaches to make sure that they no longer reflect a School of Oriental Studies point of view, the London point of view, the Eurocentric point of view. We are not the only people in the world doing this today. I think it's being done in Africa, in the West Indies-Eric Williams's book about the West Indies, for instance, is fundamental. It's been quietly done, by implication, in the novels of Wilson Harris. It's been done to some extent in the novels emerging from India. It is a creative correction of points of view. But for us in Singapore? We are a nation of migrants, really. We are, in that sense, an artificial creation, but an artificial creation that is absolutely vital and viable, because of the geographical situation of Singapore. It is an important place, geographically. So the only thing we have to do-in a sense a very massive thing-is to make sure we emerge-as a people. The people who came to Singapore from say 1819 up to perhaps just before the Second World War-there was a small influx after the Second World War-had to function as an economic unit. When you are a colony ruled by the British, the various smaller societies function by and large within their own ambit. Then the Chinese lived, on the whole, amongst themselves, the Indians lived amongst 
themselves, and so did the Malays. The Indians have their temples, they have their religious ceremonies, and so on. Their social life was based largely on an export version of what happened in South India; so also with the Chinese. Their social history, therefore, was lived but not recorded. There was no one to record that history and in any case, people who are migrants are conscious of their history in their homelands, and not so much in their places of exile. They didn't see themselves, their lives in Singapore, as being important, as being potentially unique because they always took their sense of directionin custom, in politics, in fashion, in taste-from their homelands, either through a continuing relationship or through a recall, through mythology, beliefs and prejudices of the society in their motherlands. For us, now that we have become an independent nation, a republic-we have our UN representative in New York-we need to go back, really to look at our historical as well as our social past.

Social history is not history consisting of traumatic events but a history of the family, of ordinary people; and literature is made out of the lives and experiences of ordinary people. This kind of historical continuity we must attempt to construct. The British, of course, weren't interested at all. The various ethnic groups weren't really interested in their lives in Singapore because to some extent the feeling of being exiles, the feeling of being dominated by and attached to the motherland, persisted to at least the midfifties. But social history is important because out of it you construct your types-which are necessary. If you don't have them, you can't see the evolution in your own society, and therefore your writing can only be confined to the contemporary, devoid of a historical perspective. The historical perspective is important for us because, after all, Singapore is such a small place, because it is modernizing so rapidly, becoming a kind of international city. We are in danger of losing our historical hinterland.

$P N$ : You mentioned Wilson Harris and the question of a hinterland. I notice in your poems the reflection of a Singaporean problem which is also a Third World problem. In "Ahmad," you talk of "Groping for a neutral gentleness" - a kind of hinterland of common humanity as opposed to a hinterland of a glorious Chinese or Indian past. But the connection with Wilson Harris is one of similarity and dissimilarity. Singapore is a small city-state, as you said, with just over two million people, whereas in Guyana you have fewer than a million people, with nearly all (except for the Amerindians) on the coast, with a vast physical hinterland behind. The physical problem for Wilson Harris and for you would then be different, while the psychic and metaphorical problems seem similar.

ET: You are right in saying that the psychic and metaphorical problems are similar. When I use the word "hinterland," I'm really using it as a portmanteau word. It sums up a great number of vital things. By "hinterland" I mean a culture, a past, also a sense of geography, a sense of place in which myths and legends have grown, in which people have lived and have 
gone through a rich body of experiences. For us the "hinterland" is curious, because it is both place and idea. In Singapore, we can't have place; Wilson Harris can have place as well as idea. So what do we have? We have been told again and again that we belong to the great Asian traditions. There is some truth in this, although I would like to modify it because basically, as I said in my introduction, migrants are drawn from the lower classes so they aren't the best cultural examples. What migrants bring to a new country is an idea of what they are, either as Indians or Chinese, and a popular idea of what their past, their inheritance, represents. Because we are small, we need to construct this psychic hinterland. We know we can't have a physical one. The facts of modern politics have overtaken us. It was possible at one point to refer to Malaysia. Conrad does so, and Wallace-the great biologist after whom the Wallace Line was named-can refer to "Malaysia" and mean the whole area. But we can't, because modern politics has overtaken us. Physically, we are an island of 224 square miles-226 square miles at low tide. So the kind of "hinterland" I refer to is not straight from history, but is the psychic inheritance which anybody in India, perhaps in Japan, or even in an oral society in Africa has, and which he can carry with him as part of his consciousness; and not merely as his consciousness, but also as a living part of the language, the emotions, the social institutions. In other words, the whole fabric of what we consider both the background to a culture and the culture itself. We are busy constructing a common culture out of the very diverse elements we have inherited, and therefore the creation of this hinterland is important because it really is the base upon which all writing ought to rest. Singapore writing in the meantime, before the emergence of this hinterland, will provide the kind of Singapore identity that is needed. This is why in my poems I talk about these various experiences.

PN: In "Ahmad," you end,

\author{
Will there be time, \\ For us, for me \\ Groping for a neutral gentleness \\ To reach him without burning, \\ To life into laughter?
}

Is this a challenge? Are you as poet saying, will there be time to discover and create our common humanity or are we going to be overtaken by events? ET: Yes. Because after all, with plural societies, once you achieve independence you have a multi-cultural society. We are busy searching for bridges between our cultures. These cultures aren't cultures that normally would have found themselves immediate neighbors. If you look at cultural diffusion throughout world history, the penetrations have never been really traumatic. They have only been traumatic in terms of the events, not at the cultural base. There has always been enough shared within the cultures for them to adapt. 
But here you have Chinese who are Taoist, Buddhist, or pragmatists, who are moved ultimately by an ethic rather than a religion. You have Indians who are Hindus, Sikhs, and Muslims. The Malays are Muslims. Then of course within every race you also have the whole gamut of imported Christianity. Where else in the world can you show me that kind of mixture?

Hence the sense of tension, of racial tension as supported and defined-and in a way encouraged-by political tensions. I am referring specifically to the racial riots that erupted in our part of the world. I'm talking about Singapore and Malaysia. In 1950 we had the Maria Hertog riots. They were religious in origin, i.e. Islam versus the rest. A Dutch girl had been adopted by a Malay family who naturally arranged for her to marry a Malay. Her Dutch parents discovered this, and took her back. It created one hell of a furor in colonial Singapore. In 1964 there were riots, politically motivated, but basically between the Chinese and the Malays. In 1969 there were the May 13th riots in Malaysia between the Chinese and the Malays again. I am not saying that they are simply and completely racial in origin. You have, of course, a certain style of politics on each side. You had the communists trying to fuel the fires, as it were, and so on. The whole thing was very complicated. But the point is that whatever the reason, there was animosity between the various ethnic groups.

We need to build these bridges because in every culture, I am convinced, there is a center, a humanistic center. The humanistic center sometimes is outward-looking, sometimes inward-looking. There is a chance for communication between these centers but we need time. The British on the whole were not concerned with forming a homogeneous society: they were concerned with ruling the place. They were interested in our part of the world for their reasons, not ours. They didn't have to live our lives. What they thought was "good" for us was what was actually good for them. Among the things I believe good for us would be the building of these bridges between the various communal groups, not superficially but fundamentally. The fact that you and I speak the same language is not enough. The language should reach back and bring with it, for you and for me, the communicative genius of our people so that when we use language, there is this kind of penetration, not necessarily agreement, but understanding.

$P N$ : I wonder if there hasn't been much more contact between the people of different racial groups than they themselves realize. For example, you come from a Chinese and Indian background, but I see you as a Singaporean. It's clear to me that there must have been a lot of intermingling in Singapore. Perhaps you, personally, have a unique advantage-that you do not completely fall into one group or the other?

ET: That's interesting. There has been an increasing degree of contact between the various communities, but under the British this was minimal. It was limited to very practical things, to meeting at the market, to greeting neighbors, but there was little cross-cultural contact between those who 
spoke only their own languages, the vernaculars; because for them, the major substance of their life occurred within their language groups. For instance among the Chinese, you have various communities, each speaking a different dialect. The further back you go, the more you will find that these communities, on the whole, existed within themselves. Their contact with other communities was the kind imposed by the need for trade, for mutual survival and so on.

This kind of cultural interpenetration accelerated during that period when British power was being gradually dismantled. But as soon as the British moved out and political power comes into the hands of nationals, there is, paradoxically, a terrific resurgence of ethnic identity-because now, if I belong to a majority group, I share political power, and therefore I want this place to be shaped the way I want it, according to my feelings and thinking. $P N$ : It's a common neocolonial problem. We don't want colonialism, we want to write our own history. Then they go, and you find that your own history is many histories that were yoked together at a certain point by colonialism, and not given a chance to create something new. By history, I mean not only the actual events but also the consciousness of events. Do you think the consciousness lags behind the actual events?

ET: Certainly. That, I think, is true really of many of the Third World countries. It seems to be a pattern. They go and we are left with this problem. But I think we have identified the problem and are on the road to solving it in Singapore. You mentioned someone like me, of a mixed inheritance. I was born in the thirties and at that time mixed marriages weren't many. They are becoming more frequent now. If I appear to have a fairly reasonable attitude, equipped with enough perspectives to look at the competing interests of the various groups, it is because of the English language. Ironically, the only group in Singapore who ceased to be orientated by their ethnicity were the English-educated because they intellectually moved beyond communal boundaries by achieving a view of things larger than the one normally structured by their own ethnic group or by their own vernacular languages, their own first languages. Among the English-educated you will find, by and large; a much more liberal attitude, much broader perspectives, of the problems we have; a greater capacity to identify the fundamental problems and to suggest ways out of these problems. This is one of the gifts of the English language. Colonialism is an absolutely mixed blessing; it's more sin than blessing, but there were a few blessings and English, I think, is one of the interesting remainders of any colonial experience because the English-educated were drawn from all communities, more from some, less from others; but all the same it was multi-racial.

$P N$ : So those who are English-educated are in the position of Prometheus bringing the fire back? As Fanon would have said, they have been to the centers of learning of the colonial metropolises and brought something back to the people? 
$E T$ : Sure, except for one fact-that under the colonial structure the Englisheducated, by and large, belonged to the middle-class and their interest, really, was a self-seeking one. There were exceptions to this general rule, so that, while they were able to bring back this kind of understanding, it took some time after independence from the British for the English-educated to see a positive role for themselves. Before that, the fact that they spoke English was a kind of economic comfort.

$P N$ : You've come back to the question of language. I am intrigued by one thing. You say in your introduction to The Second Tongue that you had to study Palgrave's Golden Treasury, which led to what follows:

\begin{abstract}
Addiction to set rhymes, 'poetic' subjects and regular metre all point to a notion of poetry which is nerveless and anaemic. The staple expressionproper, predictable, commendatory, soulful-could not disguise the paucity of feeling, leaving the language remote from actual emotional landscapes.
\end{abstract}

This was my experience too, growing up in colonial Uganda. I've never completely recovered from it. A small handful of verses have been integrated into my prose, but I have moved away from poetry to prose. In your case, you haven't moved to the novel, you've moved to poetry. How did you overcome this barrier?

$E T$ : I think there are two questions embedded in that one. The second and more important is, how does one overcome that barrier? Where the society is plural and monolithic you have this terrible problem of what types you can describe as being representative of your society. You are in a period of change, of rapid change. You have Chinese who are bilingual, you have Chinese who are monolingual, you have Chinese who have become thoroughly westernized, you have Chinese who have tried to remain traditional in the face of changes. That alone is complex enough. And this occurs, mind you, not merely in linguistic terms but also in social terms and you have the same thing with the Indians, with the Malays. Once you put the whole mix together, you can just imagine the mathematical combinations and permutations. So our problem, really, is a question of material.

Somerset Maugham claimed in 1948, in conversation with Malcolm Macdonald, who was then British Commissioner-General in Southeast Asia, that there is a fantastic richness of material in our part of the world. As an outsider he could very well say that, because he saw the richness of material not for its intrinsic qualities, or in terms of its intrinsic characters, but as an outsider, whose notion of character, of types, had already been formed by his tradition, by his novelistic practice. So he comes to our society as an outsider, picks the characters he wants, and writes about them. But as an insider, you will doubt whether the characters the outsider chooses are really representative of the matrix of your society. When I say matrix, I mean the themes, issues, types and so on. The insider usually sees the inside situation in a much 
more complex way than the outsider does. This is true of all Third World countries, of all nascent, changing societies.

For us in Singapore, I believe, drama and the novel will come well after poetry. Goh Poh Seng, for instance, has published two novels. But it's curious that his second novel has to be set in Vietnam. Perhaps because that is how he gets round this question of what types he needs to pick to structure his society-the society in his novel-the types necessary to expand and develop and judge the themes he chose. Within Singapore, our types are emerging. This act of defining them is important, complex, and takes time. The poet doesn't have to do it. He might be involved in the process, but it is not a precondition, a major preoccupation, of his writing. For the novelist, for the playwright-you being both, know what I mean.

PN: My novel, In a Brown Mantle, is the first novel about Goans in East Africa. I did think of the question, what is the effect going to be? But I used the perspective of an educaied politician who is Goan. He gets across many worlds within that one world in Africa, and his Goan history forms part of his consciousness. I wrote a political novel which didn't, in fact, make waves; nobody really objected and said, "This is unfair." But the Asian expulsion took place a few days after the novel was launched-maybe some Goans would have objected, but they were in the process of leaving. On the other hand, there may be the question of whether you are going to offend people in power.

$E T$ : I think the problem is really at that stage where whatever one says is unlikely to irritate the power groups. Moreover, the ruling party in Singapore, despite what the western press says, is liberal. I have a poem called "The Interview," about a political detainee being made to recant over TV. I think in most other Third World countries that poem would have been banned, and I wouldn't like to say what would have happened to the poet. But it was allowed. I am a Singaporean, I'm a nationalist, no two ways about it. That's my country for better or worse. I believe it's for better. There are problems. As a Singaporean, if I comment honestly and in a fairly balanced way, what happens? The powers that be will accept, and of course, when one criticizes adversely, there are ways and means of projecting this criticism. You can make it palatable; if not sweet, at least acceptable, unbitter.

Coming back to your other question, your novel goes beyond communal boundaries, it goes beyond narrow boundaries, not only in the spread of its characters but also in its preoccupations. It is Pan-Ugandan, it's East African, it's not narrow.

$P N$ : I meant it to be an African novel.

$E T$ : It is an African novel but the point is that it goes beyond the narrow confines of, say, Ngugi's The River Between. Of course in A Grain of Wheat he has Thompson, other Europeans, and so on. But if one does not have types, it is very difficult to evolve a structure; and without a structure, it is very diffi- 
cult to write a novel because the structure demanded in a novel is expansive, more detailed, than that of a poem.

$P N$ : I didn't want to write a narrow novel. But belonging to a very tiny group, I had nowhere to go but outwards. You know how tiny "my" group was, a few thousand people. Also, there was the ambivalent situation where Goans were Indians and yet not Indians, and my own special ambivalence because though Goan, my mother was born in Kuala Lumpur, Malaysia. As I was growing up, the mythified stories related by my parents about home were contradictory. I didn't hear about a paradise named Goa: I heard about Goa and another place called Malaya. In some ways, the two wiped each other out, and I had to start almost from scratch. Didn't this happen to you too?

ET: Yes, Peter. For me, the kind of things instilled came from three basic sources. One, an old lady, a relative from a village in China, who spoke my dialect and who in a sense brought me up. She's still alive, in her eighties. Next, I had my parents, my mother being Chinese, my father Indian. They spoke English. Although my mother speaks Teochew, she is actually a nonya, a Peranakan. They are basically Chinese who came to our part of the world from at least the late eighteenth century, spoke Malay, who, over the years adapted themselves extremely closely to the very force and attractiveness of Malay life. Yet they were very Chinese in their ways, and Chinese with such a rigidness that certain practices among them no longer even exist in China. It's curious that people at the fringe tend to adhere more rigidly to values, customs, and practices which have changed at the center-this is one of the dynamics of any migration of a culture. The third main source of influence, I think, was my teachers, and this includes your cousin, Philip Nazareth, the historian. Of my teachers, the one I remember best was an expatriate, a very unusual British expatriate, who introduced me not merely to literature in English but to literatures in English-he thought that Edgar Allan Poe was a great poet. He read Poe, an American!

$P N$ : I know the hang-ups that the British had against Americans-they were all "so uncultured."

$E T$ : He taught me a kind of intellectual humility: that when you recognized an idea as being superior, or as being very useful, you accepted it and gave it credit. You paid tribute to the thing, but you took it, nonetheless.

My discovery of an Indian inheritance and a Chinese inheritance, in a way that enabled me to retain that discovery as a part of the structure of my thinking, as a structure of my feeling, was something that I developed when I went to University. But I couldn't have done it had it not been for English. If I had spoken Chinese, the Indian part would have been left out. Had I spoken Tamil or another of the South Indian languages, the Chinese part would have been left out. But because I spoke English, and because the English I had been taught brought with it, through my old teacher, a certain humility, a certain ability to take new things and not be snobbish about them, I was able to read 
up on things, move into Chinese culture, Chinese history, Chinese mythology. So also with the Indian side of myself. Then it enabled me to look at the Malay, the Melanesian inheritance of our part of the world. I found that inheritance very hard to integrate into my basic mixture of Chineseness and Indianness, but that doesn't mean I don't understand it. I do, and I've also said, and I'll say it again, that perhaps the Malays are the most gracious people in our part of the world, because they are the only people here who have a fully structured society, from ruler to slavegirl.

$P N$ : By your part of the world, do you include Malaya?

ET: Malaysia, Indonesia, Singapore. After all, the Malays have been here long enough to develop this kind of structured society. When it comes to writing literature, they have the law of the people, the law of the Koran- the religious law - and the law of the Sultan. You have this fully structured Malay society so that within the region, wherever the Malays migrated, a whole society moved. But for the others, only a segment of their society settled in Singapore. And for the British who lived here, only-or mainlytheir peculiar imperial breed: among whom, we must admit, were some marvelous teachers, marvelous givers of knowledge, feeling, thought- but really, very few. So this is why in our part of the world the Malays, who have the most structured society, are the most gracious.

$P N$ : Was it in your effort to break out of a cultural capsule that you turned to African literature? You are a critic of African literature, having done your $\mathrm{Ph}$.D. thesis on African poetry. It is surprising to find somebody from the Far East who has studied African literature in such depth. You recently supervised the Master's thesis of a Ugandan, Theo Luzuka, who designed the cover of my novel. He wrote to me when he got to Singapore that you had been very far-sighted when you began studying African literature.

$E T$ : The inner justification, for me, arose from the fact that as a developing country we had a great need to look at the newly emergent literatures of countries that had shared a colonial experience with us. Perhaps the colonialism took a different shape and a different kind of intensity; perhaps there was a real struggle to achieve independence. I am thinking of a place like Kenya (as compared with Nigeria where the British never settled). I decided that there were three basic areas of writing in English: first the main tradition, the parent tradition, and the first export tradition-to America, then Australia, New Zealand, parts of South Africa - this for me is the main frame, the First World literature, a literature which is by and for Anglo-Saxons who shared a religion, a language, and so on. I thought the second area would involve a country like India where there is a large, powerful, classical tradition, where English first came as a visitor and is now one of sixteen official languages; but whatever its place, there was a powerful non-Anglo-Saxon alternative. Last of all, but, in the long term, perhaps the most fascinating, are those areas where there was an oral tradition, so that the coming of English meant the coming of literacy. (I am not suggesting that literacy is superior to an oral 
tradition; it isn't.) And there are those areas that were really artificial creations: the West Indies, for instance. There the original natives have been wiped out, and you have, instead, Negroes, you have Indians, you have Chinese-and, there being no such thing as a West Indian language, they all speak English. When you talk about a West Indian language, you really mean a certain kind of dialect of English. Or you mean a difference in pronunciation-you know, Trinidadian as against Jamaican. And, of course, Singapore is another example of this kind of creation.

So this is what took me to African literature. Naturally, as soon as you get into it, you become fascinated-because not only do you test the literature, but, to use your phrase, it also tests you. For me it involved more than that. I've always had an interest in anthropology, in religion, and related subjects. In fact, when I was a civil servant, one source of sanity for me was the reading of mythology, which led on naturally to ancient religion, social anthropology, physical anthropology, and ancient history. I discovered-and mind you, this was before 1966-a terrific paucity of writing about Africa's literature. I read a few articles by John Blacking who was working in East Africa at the time. Blacking had taught in a school in Singapore, so the name clicked for me. But very soon I discovered that the African literature itself spoke with a certain completeness that I found in none of the books in the various disciplines I've just mentioned. One thing led to another. It's part of the disease, the misfortune, of our profession that when you start on something, you end up going into it with all the energy you can muster. Only, in this case, it was not merely the acquiring of an additional field of study but also the education of a sensibility, since the experiences in Africa are quite different from those in Singapore. These disciplines offered insights, because they provided a hinterland, which I could see, for the novels. I could see the forces operating. In Singapore there was no ready hinterland to think in terms of. Our hinterlands were really ideas, countries in the mind, of the various people of our country. The experimentation with language, the phase through which the writing had to move, the debates about "the function of the writer" and so on, were fascinating. I spent years arguing, with Singaporeans, for the need-which seems so obvious to us-to read literatures outside the narrow confines of English literature!

$P N$ : How much of African literature has influenced your own work? How much has become available to Singaporeans and has had an influence? I mean, so far as it can be measured, and names named?

$E T$ : I think the influence has been really in terms of the extension of sensibilities. This is important. It is difficult to quantify, but it's extremely important-because it means that it helps to make the educated Singaporean, the teacher, the person who has gone through University, more open to new local writing; it alerts a teacher to the possibility that we can do this, we can write literature so that a promising pupil will now be treated with sympathy and understanding, in the school, where twenty years ago he would have 
been told, "Shut up, what makes you think you can write?" This is a great change: this awareness that English liteature is no longer English literature, and that English is no longer the preserve of those born in England. Anybody who uses the language, even someone in so-called, and I stress the adjective, "Darkest" Africa-mind you, we still have a few illusions about Africa and Africans sometimes think we are part of China: the mythifying is mutual! - well, we feel if they can write this stuff in Africa, hell, we can do it also. This helps to steady the nerve, to extend the nerve, for writing local literature. It also modifies the very narrow kind of academic approach to literature that the export version of the Cambridge Tripos foisted on various parts of the world. "Prac Crit" and so on. The toughness of Leavis is marvelous, but it's good largely in a well-cultivated garden where you've got to get rid of some of the cultivators, not the plants.

$P N$ : That's a garden that has been built with manure produced by our world! $E T$ : Can I make another point about the influences? That's the main thingthe modification of sensibility, the whole re-examination of the question of literature in English, that it ought not to be exclusively British literature. But, given our situation, the influences could be via poetry, the most thriving genre in our country. It's a more direct instance of one's own use of language, and it's easier to break away in poetry, from your main traditions of English poetry.

PN: You had already published a lot of poems before you turned to African literature. You have been of the first generation of Singaporean poets, allowing for the fact that that term "first generation" is tricky. How is it that you have continued to write and grow while your contemporaries fell by the wayside?

ET: In a small place like Singapore, the so-called intellectuals-I use that word with great hesitation: the "intellectual" as defined by the very label itself is actually a western formulation; I think it's one of those words we must be chary of using. I'm sure the poets and the philosophers in China never thought of themselves as "intellectuals" because the whole tradition that led to their rise would frown on some of the elements contained in the word "intellectual." Still, we'll use it for the moment. The so-called intellectuals get absorbed into power structures, administrative structures. By power, I don't mean merely political power-I mean political, economic, business, and administrative structures. And the higher you go, the less time you have to write. I'm not romanticizing when I say that every writer has to be a bit of a rebel-or, if not a rebel, have a slight ... discontent? "Malcontent" is too strong a word. Anyway, by and large, those who wrote, those with real talent, stopped writing once they left the University and got into government, into commerce, onto statutory boards and other quasigovernment bodies. And nothing succeeds like success, you see, so once they became successful members of the establishment, poetry suffered, because there isn't any tradition of writing in this setting. Also, remember that the 
whole notion of the writing of poetry, as seen in connection with the tradition in the English language, is quite different from this same idea in some of the other existing Asian traditions. Take the Chinese tradition, for example. Among the Chinese, once you are a great scholar, the chances are that you ought also to be a great poet. In that tradition there is a direct correlation between the capacity to write poetry and one's scholarship. Almost every great poet in China has been a scholar (although it doesn't follow that every great scholar has been a great poet!) and by scholar, I mean a person who knows the language, with or without a certificate. There is this tradition in Singapore. The point about the Chinese notion of scholarship bears making, because perhaps the most eminent Professor of Chinese we've ever had in the University of Singapore was someone who did not have a degree. I am told, on good authority, that he is among the twenty best Chinese scholars anywhere in the world. He wrote beautiful poetry, and I translated some of his work with him although I must add that it seemed very curious, in the twentieth century, in an air-conditioned room, to translate poetry written in the T'ang style!

$P N$ : By touching on that depth of tradition you raise the question of myth and its value to society.

ET: Oh yes, definitely. We haven't been able to re-create in Singapore a myth-oriented society. We come from myth-oriented societies, but we haven't been able to create a comparable ambience and resonance. We have a series of sub-myths, each a sub of something outside. I touched on this vis-a vis our own situation years ago, when we came into contact with and sought to move into and absorb Chinese mythology, Hindu mythology. Those are massive undertakings and I've never completed them because you can't really. Mythologies are deceptively open-ended in the sense that they are continually revealing, subtly instinctive. Even if you complete the reading of dominant myths, that's not enough. You've got to think and feel myths. Recreating becomes pointless, because entering myths is not a search for information but a search for processes, processes that can bring thought as well as feelings into a single act of mind. This great capacity to classify myths the way they classify folk tales is respectable futility. I tried that too and I know the time isn't ripe. But perhaps the time will never be ripe, because by urbanising, we are creating types who see far less a need for a myth-oriented society, who see more of a myth-pragmatic society, which means people who would be more immediately sympathetic to Camus, Sartre, and not to the majestical, instructive, liberating power of the Mahabharta or the Ramayana or the Li Sao or the I-Ching. The young will never acquire the capacity to appropriate and analyze their significance, are consequently not aware of their loss; they wouldn't see it as a loss, because they automatically see themselves as being in an urban situation, subject to urban pressures, and therefore identify very quickly with the kind of fragmentation that occurred first in the West. Every Asian country is emerging from a phase of history 
which is metaphysical into the physical: into physics, into industrialization, into modernization. Of course, we too will begin to have our fashionable traumas. We will start having our psychologists and our psychiatrists. But why has this come about? The answer is fairly simple. It has come about because history took certain courses in Western Europe-and that is precisely the course we are trying to set for our own countries.

The alternative is that you don't re-structure the myth. You can tap the myth because the myth has shaped the language and if you learn the language, its dominant symbols enter into you. If I were to make the "sign of the cross," even the atheist would know what I mean and feel its power. It doesn't mean he subscribes to it. In other words the recognition of its value in certain circumstances is quite apart from its value as a symbol, its weight as a symbol. But there is recognition, nonetheless.

PN: Edwin, I have with me your book of poems, Gods Can Die. Have you arranged the poems in a chronological order?

ET: Perhaps I should give you a bit of background information. The writing of verse in our part of the world was something that had been going on for a long time, but the writing was a very personal, a very individual effort. I have been able to trace some "heroic couplets" written in the thirties at Singapore's Raffles College, by people who'd studied Pope. I know there've been sonnets of various kinds written on various occasions in various styles. That kind of occasional writing has always been going on- as it has in other parts of the world where English took root. But it was only after the Second World War, at the time when the University of Malaya (then in Singapore) was founded on 1st October 1949, when the sense of nationalism, of wanting to have a nation and within that nation a common culture, started acquiring sinews; it was only then that the writing of poetry was seen as something more serious than being merely occasional. Take the study of economics, for instance: the economics studied earlier was classical, Keynesian. But even the study of economics started to change. There was a desire among the more intelligent undergraduates and graduates to see these principles in terms of local conditions. So also with the study of history. There was a medical doctor, Joseph Tan Kwan Meng, I think, who wrote articles on the history of our part of the world, and in particular on the latter part of the colonial phase we were still living under. There was an attempt to re-orientate our history. In other words, academic activities were beginning to be infused with a sense of our needs. It was part of a total movement, a gradual but total movement, the dawning not merely of the idea of nationalism, but of how this idea had to permeate into almost everything. People started asking questions. Why did we have to study Latin? Why did we have to do European geography? Why did we have to study our history in terms of Portuguese, Dutch, and British expansion overseas? Why didn't we do any Indian or Chinese history?

Let's not forget that during that period, much of the political inspiration for the English-educated came not so much from Britain as from India. The 
struggle for independence was exemplified in Gandhi, Nehru, Subhas Chandra Bose-all renegades to the diehard colonialist but to us nationalists of the first order. Things in Indonesia moved much more rapidly against the Dutch, and Sukarno was forced to declare Indonesia independent. The Philippines-I am sure it was happening there too, because there is a terrific tradition of revolt there, of assertion, of national independence and identity which started even before Rizal. Rizal was perhaps the most symbolic figure, because in him you have an image of the totality of the Filipino crisis. In our part of the world we never had any great political struggle, and therefore no great political figures. But at that time, if you wrote poetry you had to explore the needs of what you thought to be poetry.

Fortunately, or unfortunately, I am the oldest practicing Singapore-born poet writing in English. There were others before me, from whom I've learned, poets like Goh Sin Tub and Wang Gungwu, who was a Malayan. (Both were at the Univeristy of Malaya then in Singapore).

$P N$ : Looking at your poems, there is a pattern that works its way through the book, even though they cover a period of more than 20 years, from well before independence to well after. A pattern which is also suggested by its striking cover, a sequence of gods who are yet the same. The poem "Yesterday" ends,

\author{
Yet walk to the shadow \\ of Mandai mountain, \\ I will show you a \\ sleeping secret stream.
}

Is this the hinterland you were talking about?

ET: That's it. It's a kind of hinterland that comes from accumulated memory. What Wordsworth called "spots in time" in Book 11 of The Prelude. He says, "There are in our existence spots of time,/which with distinct pre-eminence retain/A vivifying Virtue." He encapsules his basic experiences. "Yesterday" represents the past as it was for me at that time. But returning to your original question: you notice the early poems are attempts to define my geography for myself but, more important, to define my geography in the English language, not in my vernacular. Before the language takes root, the geography of your country is available in you as you grow up. It's part of your maturing, it's part of your growth but the important thing is to locate that geography, not merely the physical geography but the psychic geography, the whole set of symbols, the whole stretch of your consciousness in the language you want to create. It is through this process that you change the language, and make it your own; you decolonize it.

"A Boy Drowns" is for me an important poem. It is a kind of anthropological statement attached to a piece of local history which gives it a context, dealing with questions of traditional beliefs and with new attitudes. A young man, an undergraduate, brought up along scientific lines, is con- 
tracted with those who believe that there is likely to be another drowning, as an annual affair. This belief is quite common in Asia. I am told that it is a highly complex poem; of the poems I have written, most people seem to like this one. But what I would like to refer to is the use of Hanuman. Not merely as an image; as part of the functional life of the theme:

They fished him out.

Like the face of the pool,

When the wind turns and blows sorrowful,

His skin was wrinkled.

You will notice there that the long open line which has its own rhythm is suddenly brought up by a factual statement, "His skin was wrinkled," thus achieving, I hope, a balance between the two. The observation, the fact, against the emotional response to it.
And I thought of Hanuman,
Monkey and god.
For the boy, the brown body
Was hugging himself,
His hands hugging himself.
As if he felt cold while dying,
As if the spirit leaving the body
Left it gracious, in prayer.

I think that's a fairly clear, precise image whose power comes from the sound, the repetition, and the links. I tried to create a network there, to draw lines for this image to emerge. Where there is a need to repeat, I don't hesitate because I felt at that point that the strategy was useful, since it permits a greater flexibility of tone, of voice. As if by returning to the same images you are returning to the body, again and again, looking at it differently.

$P N$ : I'd like to know how you feel you have developed as a poet since you finished the book. Is your new poetry an extension of what you have done? $E T$ : There is one dimension I want to bring into the poetry, a dimension in the idiom I once had and which, in coping with the public themes, I have allowed to become dormant. I've started on a poem that is personal. Where the poetry issues out of personal relationships, man and woman, it is very inward. Moreover the nature of this relationship has undergone various transformations in our society. But $I$ have hitherto kept clear of the themes it inspires because I believe that at this moment poetry in our part of the world ought to touch on larger, public subjects. That's why I write what I write. But in a Third World situation I feel that a poet has a double responsibility. One is his responsibility to have a function within his society, but to remain a poet. It involves some sacrifice of inner voices. But the time comes when you feel you've done enough with larger themes in that as you continue to write about them there is the growing diminution of real interest. Perhaps one 
should balance the two. For a poetry that is personal in origin, by the very nature of its demands, ensures that one's idiom is kept healthy and rooted in the psyche.

$P N$ : Strikes me as very Hindu—that at different stages, you fulfill different roles, although you are the same person. Is that at all at the back of your mind?

$E T$ : It may not be at the back of my mind, Peter, but once you have put it that way, I can see the point. I started off in 1949 by writing some poems. Since then I've always been involved in the promotion of other people's works, though I have been less active of late. I help them directly, looking at their poems, talking about them, putting anthologies together, getting magazines going and so on. Now I feel I have done enough. It's time for younger people to offer to help promote the writing. As you grow older, you feel that there is a need to re-tap your inner sources, emotional sources, to keep your language vital. I must go within the self. 